\title{
Integrated reverse supply chain model for food waste based on industry 4.0 revolutions:
}

\section{A case study of producing the household waste recycling machine}

\author{
Sharareh Mohajeri ${ }^{1}$, Fatemeh Harsej ${ }^{2, *}$, Mahboubeh Sadeghpour $^{3}$, Jahanfar Khaleghi Nia ${ }^{4}$
}

${ }^{1}$ Department of Industrial Engineering, Nour Branch, Islamic Azad University, Nour, Iran; ${ }^{2}$ Department of Industrial Engineering, Nour Branch, Islamic Azad University, Nour, Iran; ${ }^{3}$ Department of Industrial Engineering, Qaemshahr Branch, Islamic Azad University, Qaemshahr, Iran; ${ }^{4}$ Department of Mechanical Engineering, Nour Branch, Islamic Azad University, Nour, Iran

*Corresponding author: Fatemeh Harsej, Department of Industrial Engineering, Nour Branch, Islamic Azad University, Nour, Iran. Email: f_harsej@iaunour.ac.ir

Received: 15 October 2021; Accepted: 11 November 2021; Published: 8 December 2021

(c) 2021 Codon Publications

OPEN ACCESS CC) (요요 ORIGINAL ARTICLE

\begin{abstract}
The present research offeres a model to the advantage of operations for the food reverse supply chain by performancing Industry 4.0 Revolutions model of expanding a fuzzy multi-phase model for the food waste gathering reverse supply chain. This study introduces, a household waste recycling machine, which symbolizes the Industry 4.0 Revolutions. Also, electric-type vehicles have been considered for collection and delivery in accordance with the Industry 4.0 Revolutions. The rate of technology has been described in recycling stations. Several methods with different technologies to recycle food waste have been selected and assessed based on the Industry 4.0 Revolutions indicators. The food wastes are sent to recycling stations, that is places maintained, operated or used to store, buy or sell wastes before they recycled with appropriate technology. The understudy model is multi-objective, maximizing the benefit of recycling and customer response and minimizing the adverse effects of environmental pollution and transportation costs. In this research, the whale optimization algorithm is applied. The present work proposes an end-to-end solution for Reverse Supply Chain Management for food waste based on the Industry 4.0 Revolutions.
\end{abstract}

Keywords: Reverse supply chain, Food waste, Industry 4.0 Revolutions, recycling machine

\section{Introduction}

The Industry 4.0 Revolutions is determined as a modern kind of organization and the total value chain of production life cycle control (Neugebauer et al., 2016). The primary aim of Industry 4.0 Revolutions was to facilitate-management of order, research and development, startups, transfer to usage, and recycling of products (Thoben et al., 2017). Environmentally, food waste contributes to climate change. As food waste decomposes, it emits a greenhouse gas, methane, which is about 28 times more potent than carbon dioxide. Project Drawdown ranks decreased food waste as the best way to decrease global warming and has hypothesized that decreasing food waste on a global scale would help to decrease 87.4 gigatons of $\mathrm{CO}_{2}$ until 2050 (Wilkinson, 2020). Food waste is major problem for all nations and has several economic and environmental repercussions (Filimonau et al., 2020). Food waste is the unused portion of edible food, which includes materials for human consumption that are subsequently lost, reduced, discharged, or envenomed (Smith \& Landry, 2021); household food waste is a major contributor to global food waste.It is the result of consumer-decisions, with regard to preparing extra-large meals, buying too much food, and not reusing food leftovers (Boulet et al., 2021). Global statistics have shown that 
close to 800 million people are facing undernourishment or suffering from starvation (Bravi et al., 2020). Global food waste is valued at $\$ 1$ trillion annually, causing a significant financial burden (Septianto et al., 2020). Scholars have ratiocinated that waste reduction must be the primary operator with recycling as a secondary operator in waste decreasing strategies (Kim et al., 2020). In this research, by making a compost machine, the wet waste is processed in a compact and dry way for recycling, and by using the intelligent recycling application system, food waste is collected from every house. The use of the green approach in the manufacturing of this device is quite evident. This device will have a significant impact on the management of the environment and natural resources, as management of food recycling is an important issue these days. Recycling is the conversion of used products in to similar or other usable products. The first point is that limited resources are not renewable, and eventually, these resources will run out 1 day. Recycling commodities results in less use of these raw resources. The second benefit is that it saves energy and also uses lower energy for manufacturing products. The third advantage is that it benefits from food waste, which if unused will spoil the surroundings and have irreparable consequences.

The solution presented in this research is composting of food waste. While universities and policymakers have considered waste management in recent decades, poor waste management has been recognized as both an economic and environmental issue (Agovino et al. 2019). Developed countries, especially Japan, started waste management early and have made significant progress in building an urban recycling system (Geng et al., 2010). Studies and conclusions of several articles in waste management have proved that it can be effectually waste a composted minimum of 27\% (Neugebauer and Solowiej, 2017).

However, while $68 \%$ of household waste can be recycled or composted, only a tiny fraction is recycled.

Waste recycling conserves environmental resources, reduces energy consumption, greenhouse gases, costs and ameliorates climate change, and reduces costs (Waqas et al., 2017). In this research, the approach of the Industry 4.0 Revolutions has been used. In this regard, the Internet is used because the world is facing sustainable challenges and technological advances in digitalization and automation. Industry 4.0 Revalutions encompasses the digital, physical, and biological universes and influences the whole industry. The categories of Industry4.0 Revolution will be implemented not just in future industries but will also have negative and positive effects on the nature of the world of business (Waqas et al., 2017). Development towards the Industry 4.0 Revolutions has already had a significant impact, and this is based on the creation of intelligent factories, intelligent products, and smart services that use the Internet and services embedded on the Internet (Stock and Seliger, 2017). The construction of an intelligent food waste recycling machine will significantly help optimize recycling methods and prevent further pollution of the enviroment and adverse effects on human health. Reverse logistics is characterized as all coordination exercises for items that have come to the conclusion of their lifetime or need an arrangement of forms to progress. One of the usage of reverse logistics and one of the essential coordinations practices within the show term is collecting civil waste, which starts with rubbish collecting and finishes with the waste reusing handle (Habibi et al., 2017).

On the other hand, the world also faces technological advances in digitalization and automation in addition to sustainable challenges. A range of new technologies can define Industry 4.0 Revolutions. The Industry 4.0 Revolutions paradigm advances the relation of physical points like devices, sensors, and organizational assets connecting with the Internet. In this study, a model for the reverse supply chain of food waste has been propounded with uncertain situations based on the model of the Industry 4.0 Revolutions. The supply chain contains distributing stations, collecting stations, customer stations, recycling stations, and landfilling stations. In this model, food waste is collected from customer stations and sent to recycling or disposal stations. Recycled food wastes are sent from recycling stations to distributing stations and to customer-stations. Electric-type vehicles have been considered for collecting and delivery in accordance the Industry 4.0 Revolutions. Also, the technology rate has been defined in recycling centers.

Giacomo and Giosp (2019), in an article entitled, "Recycling and Waste Production: Estimating the Impact of Recycling Programs on Resource Reduction" postulated the following results:

1. A $10 \%$ growth in recycling is related to 1.5 to $2 \%$ reduction in whole urban losses.

2. Collecting programs decrease waste generation by around $4 \%$, increase recycling by about $10 \%$, and raise the marginal influence of recycling on the minimization of waste. Minimum 23\% of the all impact occurs just if That recycling is the conclusion of this program. Almazán et al. (2019), used structured surveys to extract information on household waste disposal methods and identify the most critical features to encourage household participation. Participation in waste collection services will provide a suitable alternative to the current waste management strategy, such as economic incentive programs and considering the importance of environmental conditions and the role of women and children in waste management and recycling. 
In an article entitled, "Intrinsic Motivation in Household Waste Recycling: The Case of Italy in the Year 1998," a 1998 Italian study using a data set from the Italian National Institute of Statistics and five probit models, provides an insight into the non-economic factors that drive household recycling activities.

The above article deals with the direct relationship between (i) production and disposal of waste, (ii) pollution, (iii) climate change, (iv) reduction of resources and (v) environmental changes and recycling.

Werffa et al. (2019) used a multilevel modeling method that uses all the experimental measurements; it was concluded that information strategies could Increase the effectiveness of these strategies and the consequences and results, effectively reducing household waste.

Bottani and Casella (2018) investigated the sustainable closed-loop supply chain by decreasing environmental pollutant- emissions. They developed a model for this problem and solved it using a simulation tool for a case study. Tosarkani and Amin (2018) investigated the multi-product closed-loop supply chain in the battery industry. They developed a multi-objective mathematical model and solved it using the Epsilon restriction method. Liu et al. (2018) studied the Internet of Things as a reverse supply chain stimulator (amplification). A real-time data assessment model with the capacity of IoT is created to detect and record real-time logistics data in the survey. Wang et al. (2018) investigated reverse logistics optimization for bicycle sharing and bicycle recovery. In this study, logistics costs and reverse customer satisfaction have been observed in significant areas. The model creates a reverse logistics network for defective shared bicycles. A modified genetic simulated algorithm has been used to solve the model. The results confirmed the usefulness of the modified genetic simulated algorithm. Casper and Sundin (2018) repeating of reverse logistics, packing, transporting and reverse material current to vehicles. This study aimed to prepare the structure for managing reverse material circulation in the car industry, affirming reproductive processes.

Zhou et al. (2019) investigated the development, challenges, and early experiences of systems based on COPD disease management. The system consists of mobile APPs, a spirometer, a $1 \mathrm{M}$ box, and a database that utilizes a 1M box to collect cure data from the Qingpu Branch of Zhongshan Hospital, the largest healthcare provider, and follow-up information for stable patients from 11 primary hospitals. Intelligent applications for mobile were made for the sick and physicians to institute direct connections to improve sickness control. The outcomes showed that the IoT system facilitates the collecting, storing, conducting, and analyzing of information and improves COPD managements excellent potential. Manavalan and Jayakrishna (2019) investigated IoT in a sustainable supply chain for industrial needs based on the Industry 4.0 Revolutions. Their study aimed to inquire about the different aspects of supply chain management and the Industry 4.0 Revolutions and discover potential opportunities in the sustainable supply chain with IoT to transform Industry 4.0 Revolutions. In the study, the practical factors of the sustainable supply chain were comprehensively evaluated. According to this investigation, a framework was proposed to assess different perspectives of supply chain readiness to meet the requirements of the Industry 4.0 Revolutions. The model's conceptual framework has been made up of five crucial perspectives on supply chain management, including trade, technology, sustainable development, cooperation, and management strategy. This research provides criteria that companies can evaluate to achieve numerous studies that have ever been conducted on reverse logistics problems and developed readiness for change in Industry 4.0 Revolutions. Producing household waste recycling machine, a way for reverse supply chain by using Industry 4.0 Revolutions. It has not been conscious in last studies and the present study is new in this field. Following these explanations about the reverse supply chain and Industry 4.0 Revolutions.We will explain the construction of an intelligent home composting machine, which will significantly help optimize recycling methods and prevent further pollution of the earth and human and environmental health. In general, waste separation on a wet and dry basis is important in food waste management and different devices for waste separation take different steps for recycling. In this plan, the primary focus is on building a device that can help the recycling cycle in the Industry 4.0 Revolutions, generate income for households, and ensure the industry's sustainability.

Stratman and Novak (1971), introduced a waste compactor (Figure 1).

It should be noted that the device intended for this waste compaction is bulky. The mechanism of the device is shown in Figure 1.

Borowski et al. (2013), registered a container that is used for waste disposal and recycling. This container has several partitions so that people can put different wastes separately, which makes recycling easy.

In 2013, CN 104670533A, a Chinese patent, a new method for waste recycling was introduced. In this method, waste is collected purposefully for recycling. This method uses wireless electronic technology to collect garbage bags that contain targeted materials for recycling. 


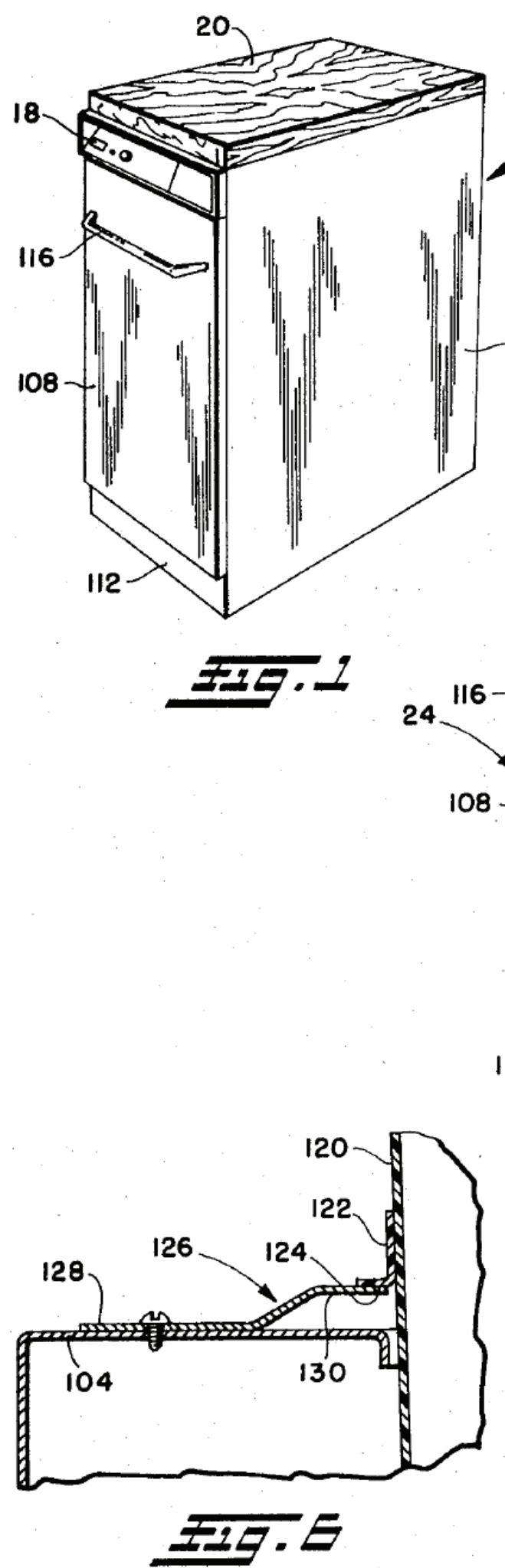

INVENTORS.

JEROME F. STRATMAN JOHN NOVAK

Br

Dberlin, Maky, Donnelly, E Renner.

Figure 1. Patent device (Stratman and Novak, 1973). 
In 2015, CN 204545223U, a Chinese patent, a recycling machine was introduced. This recycling machine is used for shredding waste plastics and automatic packaging of plastic powders. The machine includes a plastic crusher, a plastic powder receiving machine, transport and packaging bins located on either side of the plastic powder receiving machine used to carry plastic powder.

In 2015,CN 105202546A, Chinese patent, a machine for recycling waste was introduced. The schematic of the device is in Figure 2. This machine deals with waste pressing straightforwardly.

In 2015, CN 204448233U, Chinese patent, a solid organic waste recycling machine was invented. This consists of a feeding system, a pyrolysis furnace, a heating system, and an evacuation system. The apparatus is equipped with a preheating chamber, a furnace body, a pulp chamber, and a comb from top to bottom.

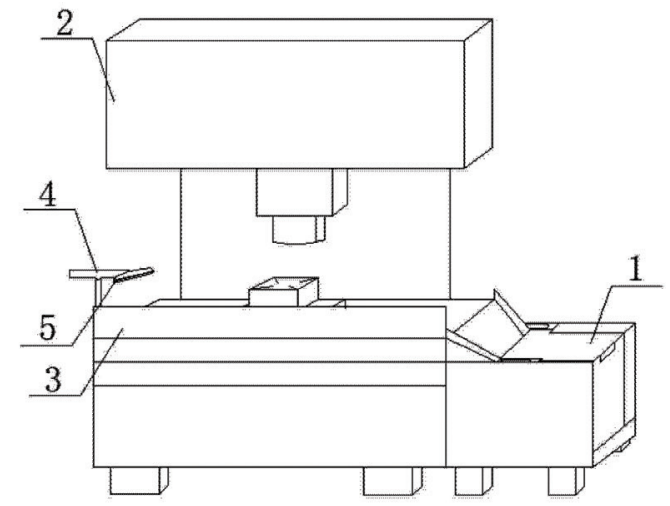

图 1

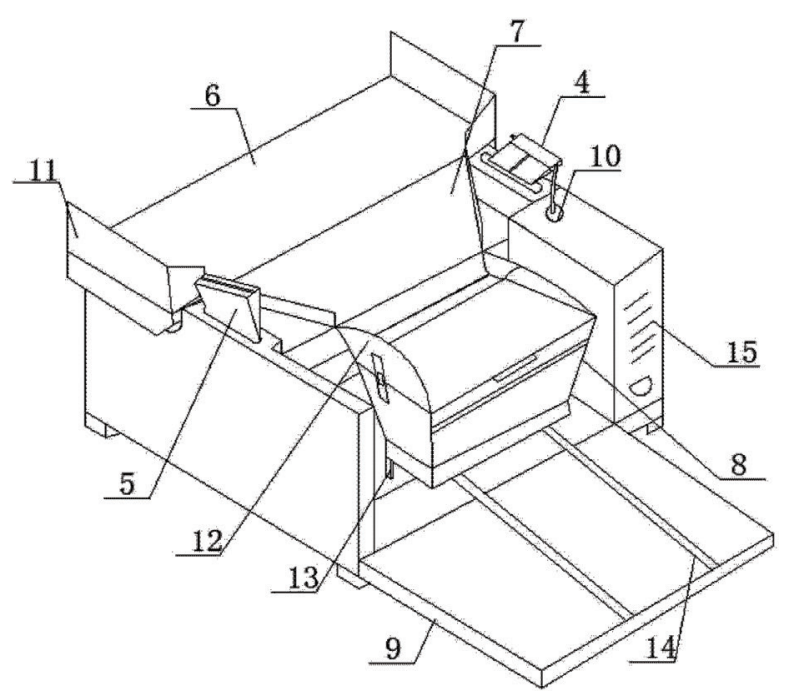

Figure 2. Patent devices 105202546A, Chinese patent (2015).
In 2018, KR 101870415B1, Korean patent, an environmentally friendly waste recycling device was introduced. This device includes a feeding device, a crushing chamber, and a screening chamber in which the lower part of the feeding device is connected to the crushing chamber flux hopper. Inside the crushing chamber is a crushing roller. To the right of the first crushing roller is the second crushing roller. The first and second crusher rollers are connected to a drive motor via a rotary shaft. This machine can collect and dispose of concrete waste and stones at construction sites. In other words, this machine turns waste into wealth.

\section{Methodology}

This study used Gray fuzzy number analysis, VIKOR method, and archival multi-objective whale optimization algorithm(WOA) to measure the effective technology criteria and solve the mathematical model.

In step one, multi-criteria decision subject has $\mathrm{m}$ nonprofit drafts containing A1, A2, A3, .., Am-1, Am and n basis containing $\mathrm{C} 1, \mathrm{C} 2, \mathrm{C} 3, \ldots, \mathrm{Cn}-1, \mathrm{Cn}$. N criteria measure every option. The full valuation is related to the drafts by contemplation of X's decision matrix $\left(=x_{i j}\right)_{m \times n}$. In the next step, the VIKOR method algorithm was used. Then, for the proposed algorithms structure, the WOA was used. At the last step, the NSGAII algorithm was applied as like as WOA.

\section{Problem Definition}

This model-s specifications and capabilities in the effective technological factors of choice for waste disposal, collecting, and recycling have been considered in Table 1.

The understudy reverse supply chain of the present research contains the steps of distributing stations, clients, collecting stations, recycling stations, and landfill stations. In the proposed model, wastes are collected from client stations and sent to recycling or landfill stations. Recycled wastes are sent from recycling stations to distribution stations and from distribution stations to clients. Electric-type vehicles have been considered for collection and delivery accordance with the Industry 4.0 Revolutions. Also, the technology rate has been defined as in recycling stations. Several methods with different technologies to recycle wastes have been selected and weighted based on the indicators of the Industry 4.0 Revolutions and the wastes are sent to recycling centers based on the technology weight. 
Table 1. Effective factors.

\begin{tabular}{|c|c|}
\hline Dimension & Subcomponent \\
\hline \multirow[t]{4}{*}{ Technological } & Intelligent and connected devices \\
\hline & $\begin{array}{l}\text { New data acquisition and technologies of } \\
\text { communication }\end{array}$ \\
\hline & Resilient infrastructure \\
\hline & Standards of technology \\
\hline \multirow[t]{3}{*}{ Economic } & $\begin{array}{l}\text { Costs of investment for the development of } \\
\text { technology and localization }\end{array}$ \\
\hline & $\begin{array}{l}\text { The efficacy of process that choosing in the } \\
\text { commercial time }\end{array}$ \\
\hline & Technology transfer costs \\
\hline \multirow[t]{3}{*}{ Social } & Citizen joining in \\
\hline & Green behavior \\
\hline & Stakeholders intelligently cooperating \\
\hline \multirow[t]{3}{*}{ Environmental } & Green collection, recycling, and disposal \\
\hline & $\begin{array}{l}\text { The issues relevant to contamination and emissions } \\
\text { of energy }\end{array}$ \\
\hline & Dangerous influence of end-of-technology life \\
\hline
\end{tabular}

\section{3-1. The proposed mathematical model}

$$
\begin{aligned}
\text { Min } \mathrm{z} 1= & \sum_{m=1}^{M} \tilde{f}_{m} z_{m}+\sum_{p=1}^{P} \tilde{f}_{p} z_{p}+\sum_{n=1}^{N} \tilde{f}_{n} z_{n}+\sum_{k=1}^{K} \sum_{g=1}^{G}\left(1-w_{g}\right) \\
& {\left[\sum _ { s = 1 } ^ { S } \sum _ { t = 1 } ^ { T } \left[\sum_{l}\left(w_{s} C_{k} c_{l}^{s g} L_{l} x_{l k}^{t s g}+c_{0} \times L_{l}\left(\widetilde{\rho_{0}}+\tilde{\alpha} x_{l k}^{t s g}\right) y_{l k}^{t g}\right)\right.\right.} \\
& +\sum_{l 1=1}^{L} \sum_{l 2=1, l 2 \neq l 1}^{L}\left(w_{s} C_{k} c_{l l l 2}^{s g} L_{l 1 l 2} x w_{l l l 2 k}^{t s g}+c_{0} \times L_{l 1 l 2}\right. \\
& \left.\left(\widetilde{\rho_{0}}+\tilde{\alpha} x w_{l l l k k}^{t s g}\right) y_{l 1 l 2 k}^{t g}\right) \\
& +\sum_{m=1}^{M}\left[\sum_{i=1}^{I}\left(w_{s} C_{k} c_{m i}^{s g} L_{m i} x_{m i k}^{t s g}+c_{0} \times L_{m i}\left(\widetilde{\rho_{0}}+\tilde{\alpha} x_{m i k}^{t s g}\right) y_{m i k}^{t g}\right)\right. \\
& +\sum_{n=1}^{N}\left(w_{s} C_{k} c_{m n}^{s g} L_{m n} x_{m n k}^{t s g}+c_{0} L_{m n}\left(\widetilde{\rho_{0}}+\tilde{\alpha} x_{m n k}^{t s g}\right) y_{m n k}^{t g}\right) \\
& \left.\left.\left.+\sum_{p=1}^{P}\left(w_{s} C_{k} c_{m p}^{s g} L_{m p} x_{m p k}^{t s g}+c_{0} \times L_{m p}\left(\widetilde{\rho_{0}}+\tilde{\alpha} x_{m p k}^{t s g}\right) y_{m p k}^{t g}\right)\right)\right]\right] \\
& +\sum_{t \in T}^{S} \sum_{s=1}^{S} \sum_{g=1}^{G}\left(1-w_{g}\right)\left[\sum _ { k = 1 } ^ { K } \left[\sum_{m=1}^{M} \operatorname{cost} t_{s g} x_{m k}^{t s g}\right.\right. \\
& +\sum_{p=1}^{P}\left(\operatorname{cost} p_{s g} x_{m p k}^{t s g}-v a l u e_{s g} x_{m p k}^{t s g}\right) \\
& \left.\left.+\sum_{n=1}^{N} \operatorname{cost} n_{s g} x_{m n k}^{t s g}\right]\right]
\end{aligned}
$$

\section{Model defuzzification}

In this model, the capacity and facility cost parameters are considered as fuzzy numbers. The fuzzy number ranking method of Jimenez et al. (2007) was used for the defuzzification of the model.

$$
\begin{aligned}
\min z & =\tilde{c} x \\
a x & \leq \tilde{b} \\
x & \geq 0
\end{aligned}
$$

In the present study, the ranking method provided by Jimenez was used. The Triangular fuzzy number will be written as follows in (Figure 3) if $\tilde{A}=\{L, M, U\}$ :

\section{Computational consequence}

\section{Criteria weight}

$$
\mu A(x)=\left[\begin{array}{ccc}
f_{A}(x)=\frac{X-L}{M-L} & L \leq X \leq M \\
1 & X=M \\
g_{A}(x)=\frac{X-L}{M-U} & M \leq X \leq U
\end{array}\right]
$$

Figure 3. Triangular fuzzy number.

In the ahead part, one question sheet was prepared for 10 statistic sample particulars. The data were prepared to count their mean. The counted mean values are changed to whole numbers between 1 and 7. Afterward, the whole numbers were converted to faraway fuzzy numbers, and eventually, data analysis was performed in due course. Datum are changed to distant fuzzy numbers in the decision matrix in Table 2.

After decision matrix-forming, the standardized $\tilde{R}$ decision matrix was counted. In the third stage, the spacing among the referral values and every comparison value was counted. The results are shown in Tables 3 and 4 .

In this stage, the maximum values of $\delta_{\max }^{(1)}$ and $\delta_{\max }^{(2)}$, as well as the minimum values of $\delta_{\min }^{(1)}$ and $\delta_{\min }^{(2)}$, were counted. In stage four, the values of gray rational ratios of $\xi_{\mathrm{ij}}^{(2)}$ and $\xi_{\mathrm{ij}}^{(1)}$ are also counted. The results are presented in Tables 5 and 6.

In the next stage, the grade of gray relations must be assessed by the weight of evaluation criteria presented in Table 7. Rather than determining sub-criteria weight, the rate of the approximation of gray relations and the final weight of main factors were specified in Table 8.

\section{Weighing for waste accumulation technologies}

This part aim was to superiority this selections per the fuzzy VIKOR method. Choices examined the preferences for waste technologies accumulation related to the influential parameters of selecting technology. To reach this aim, employed Table 9 statement variables.

After evaluation of technologies relative to their criteria by the experts, the expression values were first converted 
Table 2. The decision matrix.

\begin{tabular}{|c|c|c|c|c|}
\hline main & Technological & Economic & Social & Environmental \\
\hline Intelligent and connected devices & $(3.5,1.5) ; 5 ;(6.6,7.3)$ & $(0,1.4) ; 3(4.4,6.6)$ & $(1,0.5) ; 1 ;(2.5,3.5)$ & $(1,4,2.5) ; 3(4.4,5.6)$ \\
\hline $\begin{array}{l}\text { New data acquisition and technologies of } \\
\text { communication }\end{array}$ & $(1,0.5) ; 1 ;(2.5,4.5)$ & $(2.5,3.5) ; 5 ;(6.5,7.5)$ & $(0,1.5) ; 3(4.5,5.5)$ & $(0,0.5) ; 1 ;(2.5,3.5)$ \\
\hline Resilient infrastructure & $(2.5,3.4) ; 5 ;(6.3,7.5)$ & $(2.5,3.5) ; 5 ;(6.5,6.5)$ & $(4.5,5.5) ; 7(8,9.5)$ & $(2.5,3.5) ; 5 ;(6.5,7.5)$ \\
\hline Standards of technology & $(0,1.5) ; 4(4.5,5.5)$ & $(0,1.5) ; 4(4.5,5.6)$ & $(0,1.5) ; 4(4.5,5.5)$ & $(0,1.5) ; 4(4.5,5.5)$ \\
\hline $\begin{array}{l}\text { Costs of investment for the development of technology } \\
\text { and localizating }\end{array}$ & $(0,0.5) ; 1 ;(2.5,3.5)$ & $(0,1.4) ; 3(4.5,5.5)$ & $(0,0.5) ; 1 ;(2.5,3.5)$ & $(0,1.5) ; 3(4.5,5.5)$ \\
\hline The efficacy of process in selecting the commercial term & $(0,1.5) ; 3(4.5,5.5)$ & $(2.5,3.5) ; 5 ;(6.5,7.5)$ & $(0,1.5) ; 3(4.5,5.5)$ & $(2.5,3.5) ; 5 ;(6.5,7.5)$ \\
\hline Technology transfer costs & $(0,0.6) ; 1 ;(2.5,3.5)$ & $(2.4,3.6) ; 5 ;(6.5,7.5)$ & $(0,1.5) ; 3(4.4,5.6)$ & $(2.5,6.5) ; 4 ;(6.5,7.5)$ \\
\hline Citizen joining in & $(2.5,3.5) ; 5 ;(6.5,7.5)$ & $(2.5,3.5) ; 5 ;(6.5,7.5)$ & $(4.5,5.5) ; 7(8,9.5)$ & $(2.5,3.5) ; 5 ;(6.5,7.5)$ \\
\hline Green behavior & $(2.5,3.5) ; 5 ;(6.5,7.5)$ & $(0,0.5) ; 1 ;(2.5,3.5)$ & $(4.5,5.5) ; 7(8,9.5)$ & $(2.5,3.5) ; 4 ;(6.5,7.5)$ \\
\hline Stakeholders intelligently cooperating & $(2.5,3.5) ; 5 ;(6.5,6.5)$ & $(4.5,5.5) ; 7(8,9.5)$ & $(2.5,3.5) ; 5 ;(6.5,7.5)$ & $(0.5,3.5) ; 5 ;(6.5,7.5)$ \\
\hline Green collection, recycling, and disposal & $(3.5,3.5) ; 5 ;(6.5,7.5)$ & $(4,5.5) ; 7(8,9.5)$ & $(2.5,3.5) ; 5 ;(6.5,7.5)$ & $(2.5,3.5) ; 6 ;(6.5,7.5)$ \\
\hline $\begin{array}{l}\text { The issues relevant to emissions of contamination and } \\
\text { energy }\end{array}$ & $(2.5,3.6) ; 5 ;(6.5,8.5)$ & $(5.5,7.5) ; 9 ;(9.4,10)$ & $(4.5,5.5) ; 7(8,9.5)$ & $(2.5,3.5) ; 5 ;(6.6,7.5)$ \\
\hline Dangerous influence of end-of-technology life & $(0.5,3.5) ; 5 ;(6.5,7.5)$ & $(2.5,3.5) ; 5 ;(6.5,7.5)$ & $(4.5,5.5) ; 7(8,10.5)$ & $(2.5,4.5) ; 5 ;(6.5,7.4)$ \\
\hline
\end{tabular}

Table 3. The $\delta_{\mathrm{ij}}^{1}$ value.

\begin{tabular}{|c|c|c|c|c|c|c|}
\hline Sub/main & Information & Technological & Economical & Social & Environmental & Legal \\
\hline Intelligent and connected devices & 0.527 & 0.788 & 0.798 & 0.685 & 0.499 & 0.922 \\
\hline New data acquisition and technologies of communication & 0.538 & 0.658 & 0.576 & 0.571 & 0.570 & 0.594 \\
\hline Resilient infrastructure & 0.525 & 0.702 & 0.556 & 0.538 & 0.541 & 0.546 \\
\hline Standards of technology & 0.511 & 0.652 & 0.539 & 0.585 & 0.542 & 0.541 \\
\hline $\begin{array}{l}\text { Costs of Investment for the development of technology } \\
\text { and localization }\end{array}$ & 0.850 & 0.600 & 0.508 & 0.563 & 0.601 & 0.535 \\
\hline $\begin{array}{l}\text { The efficacy of process that choosing in the commercial } \\
\text { term }\end{array}$ & 0.678 & 0.506 & 0.597 & 0.602 & 0.564 & 0.574 \\
\hline Technology transfer costs & 0.579 & 0.546 & 0.668 & 0.896 & 0.610 & 0.830 \\
\hline Citizen joining in & 0.624 & 0.628 & 0.623 & 0.526 & 0.606 & 0.560 \\
\hline Green behavior & 0.587 & 0.519 & 0.553 & 0.506 & 0.600 & 0.538 \\
\hline Stakeholders intelligently cooperating & 0.853 & 0.668 & 0.552 & 0.605 & 0.548 & 0.544 \\
\hline Green collection, recycling and disposal & 0.638 & 0.623 & 0.625 & 0.648 & 0.528 & 0.535 \\
\hline $\begin{array}{l}\text { The issues relevant to emissions of contamination and } \\
\text { energy }\end{array}$ & 0.518 & 0.554 & 0.492 & 0.622 & 0.567 & 0.526 \\
\hline Dangerous influence of end-of-technology life & 0.617 & 0.554 & 0.573 & 0.603 & 0.604 & 0.525 \\
\hline
\end{tabular}

into their equivalent fuzzy values, and then, the mean opinions of experts were calculated, and a matrix of the fuzzy decision was prepared. Following the preparation of the matrix, positive and negative criteria were determined, as shown in Table 10.

Following the counting standard matrix of fuzzy decision, the extent of utility measurement $\left(\tilde{S}_{\mathrm{i}}\right)$ and regret measurement $\left(\tilde{R}_{\mathrm{i}}\right)$ of $\left(\mathrm{i}^{\text {th }}\right)$ was counted (Table 11$)$. Then, the value of each parameter is calculated, as shown in Table 12.
In the next step, the value of the VIKOR index $\tilde{Q}_{i}$ was calculated (Table 13). After preparing values of $\tilde{Q}_{i}$, defuzzification was performed on these values as reported in Table 14.

\section{Solving results}

In this part, with experiential designing, problems are eliminated by genetic and whale algorithms, and results 
Table 4. The $\delta_{\mathrm{ij}}^{2}$ value.

\begin{tabular}{|c|c|c|c|c|c|c|}
\hline Sub/main & Information & Technological & Economical & Social & Environmental & Legal \\
\hline Intelligent and connected devices & 0.599 & 0.502 & 0.505 & 0.565 & 0.568 & 0.799 \\
\hline New data acquisition and technologies of communication & 0.668 & 0.539 & 0.548 & 0.598 & 0.549 & 0.576 \\
\hline Resilient infrastructure & 0.712 & 0.576 & 0.535 & 0.624 & 0.529 & 0.556 \\
\hline Standards of technology & 0.462 & 0.528 & 0.518 & 0.558 & 0.521 & 0.539 \\
\hline $\begin{array}{l}\text { Costs of investment for development of technology and } \\
\text { localization }\end{array}$ & 0.611 & 0.566 & 0.858 & 0.610 & 0.578 & 0.518 \\
\hline The efficacy of process in the commercial term & 0.470 & 0.586 & 0.555 & 0.569 & 0.545 & 0.535 \\
\hline Technology transfer costs & 0.568 & 0.514 & 0.528 & 0.512 & 0.568 & 0.522 \\
\hline Citizen joining in & 0.670 & 0.586 & 0.579 & 0.501 & 0.565 & 0.628 \\
\hline Green behavior & 0.762 & 0.491 & 0.531 & 0.488 & 0.557 & 0.506 \\
\hline Stakeholders intelligently cooperating & 0.532 & 0.573 & 0.517 & 0.557 & 0.523 & 0.617 \\
\hline Green collection, recycling and disposal & 0.559 & 0.504 & 0.866 & 0.899 & 0.501 & 0.818 \\
\hline $\begin{array}{l}\text { The issues relevant to emissions of contamination and } \\
\text { energy }\end{array}$ & 0.613 & 0.476 & 0.868 & 0.977 & 0.732 & 0.497 \\
\hline Dangerous influence of end-of-technology life & 0.729 & 0.745 & 0.741 & 0.593 & 0.699 & 0.761 \\
\hline
\end{tabular}

Table 5. The $\xi_{i i}^{(1)}$ value.

\begin{tabular}{|c|c|c|c|c|c|c|}
\hline Sub/main & Information & Technological & Economical & Social & Environmental & Legal \\
\hline Intelligent and connected devices & 0.991 & 0.989 & 0.989 & 0.969 & 0.988 & 0.991 \\
\hline New data acquisition and technologies of communication & 0.953 & 0.982 & 0.980 & 0.970 & 0.986 & 0.988 \\
\hline Resilient infrastructure & 0.973 & 0.971 & 0.986 & 0.972 & 0.989 & 0.953 \\
\hline Standards of technology & 0.993 & 0.978 & 0.991 & 0.985 & 0.991 & 0.989 \\
\hline $\begin{array}{l}\text { Costs of investment for the development of technology } \\
\text { and localization }\end{array}$ & 0.966 & 0.969 & 0.989 & 0.991 & 0.991 & 0.994 \\
\hline The efficacy of process in the commercial term & 0.998 & 0.983 & 0.977 & 0.969 & 0.988 & 0.983 \\
\hline Technology transfer costs & 0.973 & 0.991 & 0.988 & 0.989 & 0.988 & 0.979 \\
\hline Citizen joining in & 0.965 & 0.955 & 0.959 & 0.991 & 0.990 & 0.990 \\
\hline Green behavior & 0.970 & 0.989 & 0.988 & 0.988 & 0.949 & 0.979 \\
\hline stakeholders intelligently cooperating & 0.978 & 0.972 & 0.992 & 0.969 & 0.992 & 0.989 \\
\hline Green collectionng, recycling and disposal & 0.985 & 0.995 & 0.973 & 0.959 & 0.989 & 0.993 \\
\hline $\begin{array}{l}\text { The issues relevant to emissions of contamination and } \\
\text { energy }\end{array}$ & 0.975 & 0.988 & 1 & 0.967 & 0.978 & 0.988 \\
\hline Dangerous influence of end-of-technology life & 0.979 & 0.979 & 0.981 & 0.969 & 0.988 & 0.988 \\
\hline
\end{tabular}

were analyzed and evaluated. The results of implementing the two algorithms have been presented in Table 15 based on the comparative indexes.

In Table 15, the values of quality and dispersing in whale optimization comparison with genetic algorithm were up for total problems with different scales.

\section{Conclusion and Recommendations}

In the present research, the researchers summarize their main findings while also supporting the conclusions that were- drawn. In order to get the reader fully involved in the field of study, they propose suggestions for future research. Besides, other researches also attempted to illustrate this relationship between reverse supply chain and household waste recycling as follows, Ye et al. (2020) reported that the artificial intelligence system used for environmental issues may fail due to lack of data for validation and standardization due to different situations, computational time and black-box approach. Therefore, it should be noted that it can be detrimental to society without a relevant and valid data set for training and validation of a model for artificial intelligence. However, in this article, with the correct data and appropriate methods, artificial intelligence and its applications were very 
Table 6. The $\xi_{i i}^{(2)}$ value.

\begin{tabular}{|c|c|c|c|c|c|c|}
\hline Sub/main & Information & Technological & Economic & Social & Environmental & Legal \\
\hline Intelligent and connected devices & 0.987 & 0.983 & 0.988 & 0.972 & 0.983 & 0.991 \\
\hline New data acquisition and technologies of communication & 0.995 & 0.969 & 0.991 & 0.973 & 0.989 & 0.976 \\
\hline Resilient infrastructure & 0.994 & 0.982 & 0.994 & 0.975 & 0.987 & 0.969 \\
\hline Standards of technology & 0.998 & 0.986 & 0.975 & 0.985 & 0.988 & 0.978 \\
\hline $\begin{array}{l}\text { Costs of investment for the development of technology and } \\
\text { localization }\end{array}$ & 0.989 & 0.967 & 0.964 & 0.991 & 0.983 & 0.988 \\
\hline The efficacy of process in the commercial term & 0.998 & 0999 & 0.969 & 0.982 & 0.976 & 0.978 \\
\hline Technology transfer costs & 0.991 & 0.984 & 0.985 & 0.975 & 0.986 & 0.989 \\
\hline Citizen joining in & 0.981 & 0.980 & 0.982 & 0.980 & 0.989 & 0.972 \\
\hline Green behavior & 0.970 & 0.984 & 0.987 & 0.986 & 0.989 & 0.979 \\
\hline Stakeholders intelligently cooperating & 0.983 & 0.988 & 0.979 & 0.988 & 0.981 & 0.991 \\
\hline Green collection, recycling and disposal & 0.973 & 0.995 & 0.984 & 0.972 & 0.988 & 0.992 \\
\hline $\begin{array}{l}\text { The issues relevant to emissions of contamination and } \\
\text { energy }\end{array}$ & 0.994 & 0.976 & 0.972 & 0.984 & 0.979 & 0.989 \\
\hline Dangerous influence of end-of-technology life & 0.991 & 0.984 & 0.988 & 0.975 & 0.981 & 0.988 \\
\hline
\end{tabular}

Table 7. The criteria weight.

\begin{tabular}{ll} 
Sub/criteria & Weight \\
\hline Intelligent and connected devices & 0.0490 \\
New data acquisition and technologies of communication & 0.0488 \\
Resilient infrastructure & 0.0491 \\
Standards of technology & 0.0495 \\
Costs of investment for the development of technology & 0.0488 \\
and localization & \\
The efficacy of process in selecting the commercial term & 0.0491 \\
Technology transfer costs & 0.0488 \\
Citizen joining in & 0.0475 \\
Green behavior & 0.0494 \\
Stakeholders intelligently cooperating & 0.0486 \\
Green collection, recycling, and disposal & 0.0487 \\
The issues relevant to emissions of contamination and & 0.0491 \\
energy & \\
Dangerous influence of end-of-technology life & 0.0494
\end{tabular}

Table 8. The major criteria weight.

\begin{tabular}{lll} 
Rank & Main factor & Weight \\
\hline 3 & Technological & 0.0843 \\
2 & Economical & 0.0844 \\
2 & Social & 0.0844 \\
4 & Environmental & 0.0842 \\
\hline
\end{tabular}

efficient and helpful, and in the household waste recycling machine, this item was used. This device is on a much larger scale for segregation and other reverse supply chain processes in household waste recycling. Mohammad et al. (2021) and Vanapalli et al. (2021), in
Table 9. Linguistic variable.

\begin{tabular}{lc} 
Semantic term & Fuzzy number \\
\hline Very weak (VW) & $(0.3,0,0.01)$ \\
Weak (W) & $(0.5,0.3,0)$ \\
Medium weak (MW) & $(0.6,0.5,0.3)$ \\
Justly good (JG) & $(0.7,0.6,0.5)$ \\
Medium good (MG) & $(0.8,0.7,0.6)$ \\
Good (G) & $(1,0.9,0.7)$ \\
Very good (VG) & $(1,1,0.9)$ \\
\hline
\end{tabular}

Table 10. Negative and positive criteria.

\begin{tabular}{|c|c|c|}
\hline Main Item & Negative & Positive \\
\hline Technological & & * \\
\hline Economical & & * \\
\hline Social & & * \\
\hline Environmental & & * \\
\hline
\end{tabular}

Table 11. The $\tilde{S}_{\mathrm{i}}$ and $\tilde{\mathrm{R}}_{\mathrm{i}}$ value.

\begin{tabular}{lcc} 
Option & $\tilde{\mathbf{S}}_{\mathbf{i}}$ & $\tilde{\mathbf{R}}_{\mathbf{i}}$ \\
\hline loT-based technologies & $(3,01,3.96,4.99)$ & $(0.39,0.57,0.68)$ \\
Mobile-based technologies & $(2.72,3.95,4.99)$ & $(0.32,0.49,0.65)$ \\
GIS-based technologies & $(0.52,0.48,0.82)$ & $(0.41,0.58,0.72)$ \\
Web-GIS-based technologies & $(0.29,0.52,0.75)$ & $(0.33,0.48,0.72)$
\end{tabular}

a study on the epidemiological conceptions of COVID19 on food system resilience, waste management overall long-term sustainability of the food supply chain in specific situations, found that the best solution was to decrease food waste by adopting new behaviors targeted 
Table 12. Parameters value.

\begin{tabular}{lc} 
Factor & Value \\
\hline $\mathrm{S}^{-}$ & $(2,99,4.06,4.89)$ \\
$\mathrm{S}^{*}$ & $(2.68,3.89,488)$ \\
$\mathrm{R}^{-}$ & $(0.49,0.51,0.81)$ \\
$\mathrm{R}^{*}$ & $(0.31,0.50,0.78)$ \\
\hline
\end{tabular}

Table 13. The $\tilde{Q}_{i}$ values.

\begin{tabular}{lc} 
Option & $\tilde{\mathbf{Q}}_{\mathbf{i}}$ \\
\hline loT-based echnologies & $(0.809,0.981,1)$ \\
Mobile-based echnologies & $(0.2,0.198,0.199)$ \\
GIS-based echnologies & $(0.30,0.358,0.471)$ \\
Web-GIS-based echnologies & $(0.87,0.99,1)$ \\
\hline
\end{tabular}

Table 14. Preference alternative.

\begin{tabular}{lll} 
Rank & Option & $\tilde{\mathbf{Q}}_{\mathbf{i}}$ \\
\hline 3 & loT-based echnologies & 0.959 \\
1 & Mobile-based echnologies & 0.1299 \\
2 & GIS-based echnologies & 0.3798 \\
4 & Web-GIS-based echnologies & 0.968 \\
\hline
\end{tabular}

at a more sustainable consumption pattern, which in this study, while inverse supply chain stability, was intended to produce a device that recycles and manages waste. Makes food and household waste on a small scale. As can be seen in the research literature, the number of inventions in recycling devices is increasing day by day. This increase can be seen in the number of inventions in 2018 when China was working extensively on the recycling industry. Recycling, returns very high capital and high profits to the country-s economic cycle. The second necessity is the very high cost of recycling devices and the dimensions and cost of food waste collection these problems are solved with the device provided. In general, the innovation of this research can be considered in the following cases.

- Using the pattern of the Industry 4.0 Revolutions in the recycling industry.

- Using the green approach in building a home recycling machine.

- There is no need to collect waste, as the waste is ready to be recycled and delivered separately.

- Profitability for the people and the government: People make a profit by selling food waste prepared for recycling, and the government by selling household recycling equipment. This perspective has never

Table 15. Results for solving sample problems.

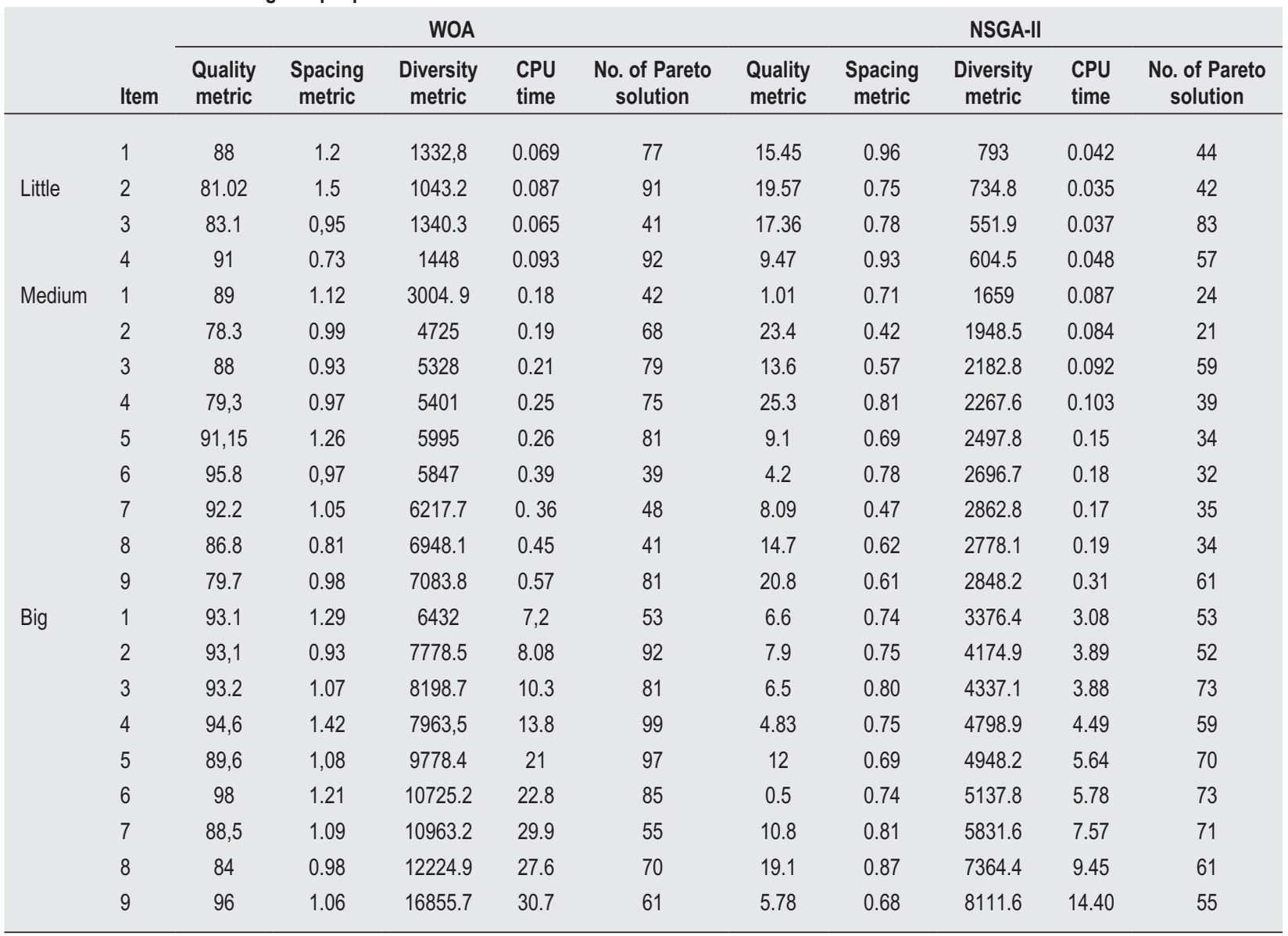


been seen in any product. In other words, this is the first time this plan has been proposed.

- The device is small in size and can be used at home. (All introduced models have large dimensions. And, the smaller models that are available cannot perform multiple tasks).

- The existing device has low energy consumption. (The energy consumption parameter has not been discussed in any device so far. In other words, it has not been considered at all, but in this device, because it is an urban device with a large number of users, the energy consumption parameter is critical).

- In the existing drying machine, the food waste mill and extruder are found in the same machine. (No urban device can perform all three operations, especially devices with small dimensions).

- Using the intelligent system of recycling applications to collect food waste. In addition to managing customer payments, the app allows customers to sell their waste to the government and receive a fee.

In construction of the claimed device, the following objectives must be achieved in the components of the device:

- Build a device that has low energy consumption.

- The weight of the device and its dimensions should be such that it can be easily used at home.

- The blades of the machine are such that they can easily pulverize food waste.

- The drying mechanism of the machine, in addition to having low energy consumption, can completely dry the waste in a short time.

- The pressing mechanism of the machine, which is manual, should be such that any person can efficiently perform the pressing operation with little effort.

In general, the device should be able to achieve the following goals:

- Dry the food waste in a short time.

- The machine can easily convert food waste into a paste.

- The machine performs the pressing operation, and finally, the pressed waste can be delivered from the machine.

- low energy consumption.

Prodution of food waste recycling machine (Figure 4):

First, the body of the device is designed, and the location of product components and peripherals is determined. Then comes the stage of selecting the heater, electric motor, and cutting and crushing blades of the product. After designing the system, the sliders of the machine are designed, followed by the design stage of the screw press mechanism, which includes the determination of the diameter and the number of screw press steps to achieve the appropriate power. In the end, the said parts are manufactured and placed on the device. The following test steps are appropriate to achieve the optimal product.

- After ensuring its efficiency, the blades and the electric motor's power for proper shredding of food waste should be checked and tested.

- Test the heater to see if it can dry $1 \mathrm{~kg}$ of food wet waste well in $20 \mathrm{~min}$ or not.

- Screw test for proper compression

This study tried to attend all potential stations in reverse logistics, containing collecting/restoring stations, recycling stations and landfills stations, with the assumptions of the confined capacity of stations being multi-product. The offered algorithms were performed in a MATLAB software environment and outcomes of their implementation in sample practical problems were comprised of others in terms of dispersion, quality, solving time and uniformity.
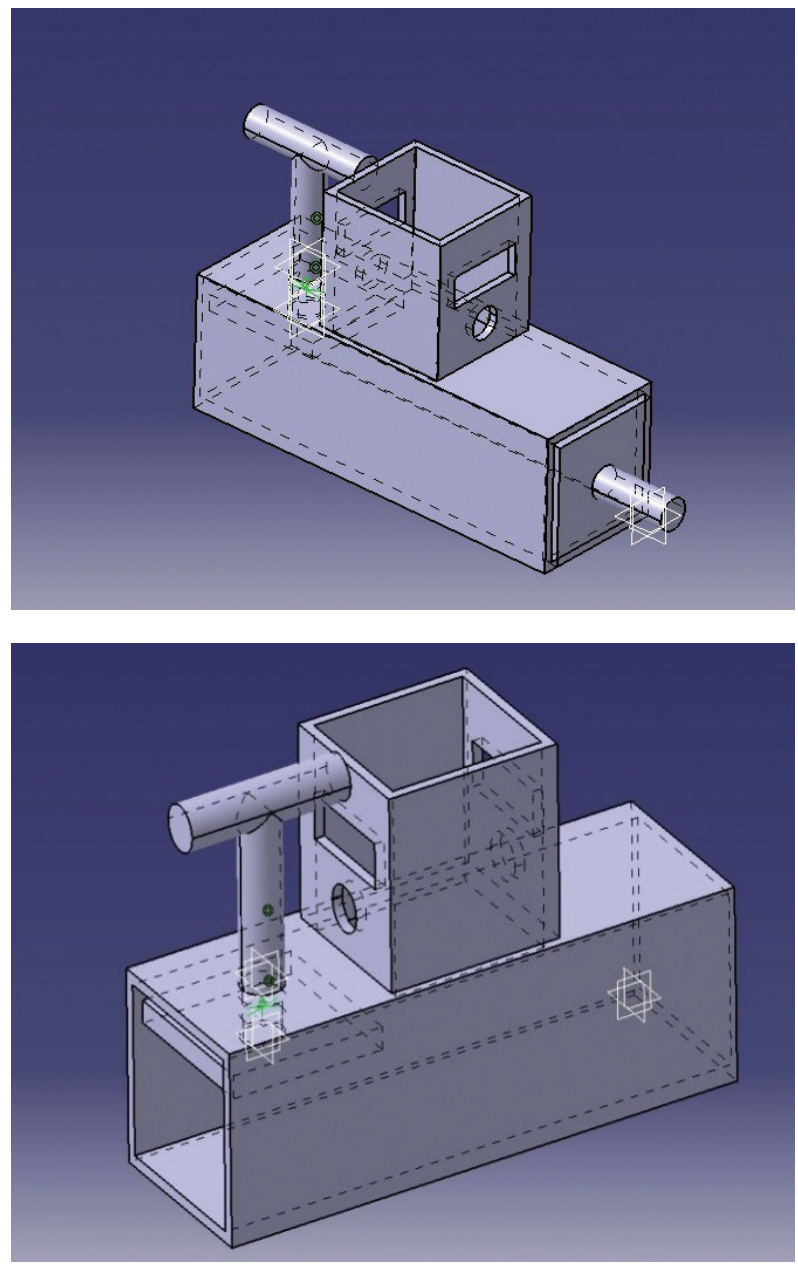

Figure 4. Food waste recycling machine details 
Today, food waste management has a special place. The use of food waste has many benefits for governments and industries. Hence, extensive investments have been made for this purpose, and different devices have been made in this field.

In particular, the following problems can be noted in the current industry concerned with food waste recycling machinery

The devices are enormous.

- The very high cost of the devices makes them available only to specific centers.

- Waste segregation should be done, which in addition to the human cost, is time-consuming on a large scale for large cities.

- Very high power consumption of devices.

- In the discussion on traditional recycling, it can be pointed out that this type of recycling causes environmental pollution, but this research approach is concerned with green recycling. In other words, in the discussion of recycling, environmental factors are critical, which unfortunately adversely affects recycling. Traditional recycling does not pay attention the adverse effects on the environment. Some of the waste that cannot be recycled is incinerated, and this creates many problems.

The following benefits can be obtained by using the current scheme.

- People are encouraged to segregate garbage at home.

- Reduces food waste management costs.

- Low cost of the device.

- The device is mobile and can be easily placed at home (small size).

- Low power consumption: The device uses a lowpower electric motor that increases the output power with the help of a gearbox. This makes it possible to achieve more output with less power. In addition, the act of pressing the food waste manually saves energy.

- Income generation for households: Income generation is based on application. In this method, first, the user weighs the waste and enters it in the application; then based on the weight of the waste, the user can inform that he or she has taken action to deliver the waste to the relevant organization and also enter his or her credit card number in the device and pre-sell waste and make money.

- Natural resources and mines in our country are limited, and the waste of these resources deprives the next generations of their needs. Recycling these items and reusing them reduces the cost of raw materials for production and reduces pollution by reducing energy consumption. The initial separation of waste by the citizens themselves and the possibility of initial preparation of recycled materials is very important. Of course, this issue can also be examined in terms of environmental parameters. In the green recycling approach, the greatest focus is on individual waste management, and given that people in the community participate in this project, we can focus more on the waste separation process. In other words, municipal waste is not removed from homes and is not left in the environment. Although waste separation is managed in the traditional recycling debate, no solution has been found for some items so far. Moreover, it ultimately causes environmental pollution. However, in this plan, in other words, the waste prepared for recycling will be delivered from the door of the house, and no pollution will be created, and the wallet will be designed and charged each time.

- Application for the device

Recycling application is an intelligent system for collecting food waste, which encourages waste producers to separate them and guides them to sell their waste and earn income for food waste producers; it plays a vital role in better waste recycling and environmental cleanliness.

Its advantages include:

- Creates and develops customer loyalty

- Applications enable direct and instantaneous communication with customers. This close relationship creates a relationship between the business and the customers, ultimately leading to brand loyalty.

- Strengthens the brand

- Creates a bold presence

- Has a more prominent presence among customers by offering promotions and discounts in the application.

- Increases accessibility

- Ensures easy access to the customer service list

- Facilitates easy purchase of a product. Customers can do this online with the app, and the app can be configured to store their information. Once registered in the application, they no longer need to enter their information into the system for each entry and purchase.

- Receives special notifications for customers

The easier the buying process for the customer, the more likely they are to buy. Making all the product information available to them when they need to collect data reduces the likelihood of buying.

Sharma et al. (2020), the fact that waste management becomes difficult for the relevant authorities during and after the global epidemic due to coronavirus 2019 (COVID-19). They have proposed incineration, chemical disinfection, thermal inactivation, and hydrothermal carbonization for waste management. This article proposes 
a more innovative and more efficient solution that eliminates the need for waste disposal, which is a precious asset. Also, for future studies, the level of use of this device can be increased, and for other household waste, industrial and urban options can also be examined.

In another research, Hossain and Thakur (2021) oncluded that logistics management in the health sector could increase performance. As in the present study, the determining factors have reached their optimal state. On the other hand, the present study developed a new reverse supply chain network for waste collection with the Industry 4.0 Revolutions, and it has implemented it with a construction proposal of producing household waste recycling machines. In the following, Valenzuela et al. (2021) reviewed the extensive literature on the subject. They explored different ways to achieve circular economics through inverse logistics. Due to the fastest-growing future waste, novel waste collection methods are needed. So, this research has investigated waste collection technologies and their influential factors. In this regard, the practical factors and different technologies were weighted. The investigative and practical technology selection results showed that the legal factor is in the first place, economic and social factors are in the second place, information and technological factors are in the third place, and the environmental factor is in the fourth place. Also, technology rankings showed that mobile-based technologies are in the first place, GIS-based technologies are in the second place, IoT-based technologies are in third place, and WebGIS-based technologies are in the fourth place.

In this research. Producing household waste recycling machine was done precisely by emphasizing these indicators. Using applications is essential for business development, and in this study, an application was designed to use it after building the device. An application-based economy can grow and open up new opportunities. In addition, the application-based economy has better control and is easy to manage.

\section{References}

Agovino, M., Cerciello, M. and Musella, G., 2019. The good and the bad: identifying homogeneous groups of municipalities in terms of separate waste collection determinants in Italy. Ecological Indicators 98: 297-309. https://doi.org/10.1016/j.ecolind.2018. 11.003

Almazán, C. S., Alfaro, J. F., Sikra, S., 2019. Exploring household willingness to participate in solid waste collection services in Liberia, Habitat International,

Volume 84, Pages 57-64, ISSN 0197-3975, https://doi.org/10.1016/j. habitatint.2019.01.001.

Borowski, D., Huddleston, W. and Thorp, B., 2013. Waste recycling method. U.S. Patent 8,459,461, issued June 11.
Bottani, E. and Casella, G., 2018. Minimization of the environmental emissions of closed-loop supply chains: a case study of returnable transport assets management. Sustainability 10(2): 329. https://doi.org/10.3390/su10020329

Boulet, M., Hoek, A.C. and Raven, R., 2021. Towards a multi-level framework of household food waste and consumer behaviour: untangling spaghetti soup. Appetite 156: 104856. https://doi. org/10.1016/j.appet.2020.104856

Bravi, L., Francioni, B., Murmura, F. and Savelli, E., 2020. Factors affecting household food waste among young consumers and actions to prevent it. A comparison among UK, Spain and Italy. Resources, Conservation and Recycling 153: 104586. https://doi. org/10.1016/j.resconrec.2019.104586

Casper, R. and Sundin, E., 2018. Reverse logistic transportation and packaging concepts in automotive remanufacturing. Procedia Manufacturing 25: 154-160. https://doi.org/10.1016/j. promfg.2018.06.069

CN 104670533A, Chinese patent, (2015). Waste recycling device with denoising function and use method thereof.

CN 105202546A, Chinese patent, (2015). Solid organic waste recycling device.

CN 204448233U, Chinese patent, (2015). Environment-friendly building garbage recycling device.

CN 204545223U, Chinese patent, (2015). Device for punch press waste recycling.

Filimonau, V., Matute, J., Kubal-Czerwi'nska, M., Krzesiwo, K. and Mika, M., 2020. The determinants of consumer engagement in restaurant food waste mitigation in Poland: an exploratory study. Journal of Cleaner Production 247: 119105. https://doi. org/10.1016/j.jclepro.2019.119105

Geng, Y., Tsuyoshi, F. and Chen, X., 2010. Evaluation of innovative municipal solid waste management through urban symbiosis: a case study of Kawasaki. Journal of Cleaner Production 18(1011): 993-1000. https://doi.org/10.1016/j.jclepro.2010.03.003

Giacomo, A. and Giuseppe, M., 2019. Recycling and waste generation: an estimate of the source reduction effect of recycling programs. Ecological Economics 161: 321-329. https://doi. org/10.1016/j.ecolecon.2019.04.002

Habibi, M.K., Battaïa, O., Cung, V.D. and Dolgui, A., 2017. Collection-disassembly problem in reverse supply chain. International Journal of Production Economics 183: 334-344. https://doi.org/10.1016/j.ijpe.2016.06.025

Hossain, M.K. and Thakur, V., 2021. Benchmarking healthcare supply chain by implementing Industry 4.0: a fuzzy-AHP-DEMATEL approach. Benchmarking: An International Journal 28(2): 556-581. https://doi.org/10.1108/BIJ-05-2020-0268

Jiménez, M., Arenas, M., Bilbao, A. and Rodrı, M.V., 2007. Linear programming with fuzzy parameters: an interactive method resolution. European Journal of Operational Research 177(3): 1599-1609. https://doi.org/10.1016/j.ejor.2005.10.002

Kim, J., Rundle-Thiele, S., Knox, K., Burke, K. and Bogomolova, S., 2020. Consumer perspectives on household food waste reduction campaigns. Journal of Cleaner Production 243: 118608. https://doi.org/10.1016/j.jclepro.2019.118608

KR 101870415B1, Korean patent, (2018). Shredding device for electronic waste recycling. 
Liu, S., Zhang, G. and Wang, L., 2018. IoT-enabled dynamic optimisation for sustainable reverse logistics. Procedia CIRP 69: 662667. https://doi.org/10.1016/j.procir.2017.11.088

Manavalan, E. and Jayakrishna, K., 2019. A review of Internet of Things (IoT) embedded sustainable supply chain for industry 4.0 requirements. Computers \& Industrial Engineering 127: 925953. https://doi.org/10.1016/j.cie.2018.11.030

Maria, C.A. and Damiano, F., 2019. Intrinsic incentives in household waste recycling: the case of Italy in the year 1998. Journal of Cleaner Production 227: 98-110. https://doi.org/10.1016/j. jclepro.2019.04.184

Mohammad, A., Goli, V.S.N.S. and Singh, D.N., 2021. Discussion on Challenges, opportunities, and innovations for effective solid waste management during and post COVID-19 pandemic, by Sharma et al. (2020). Resources, Conservation and Recycling 164: 105175. https://doi.org/10.1016/j. resconrec.2020.105175

Neugebauer, M. and Sołowiej, P., 2017. The use of green waste to overcome the difficulty in small-scale composting of organic household waste. Journal of Cleaner Production 156: 865-875. https://doi.org/10.1016/j.jclepro.2017.04.095

Neugebauer, R., Hippmann, S., Leis, M. and Landherr, M., 2016. Industry 4.0-form the perspective of applied research. 49th CIRP Conference on Manufacturing Systems, December 2016, Procedia CIRP, Volume 57, Pages 2-7, Munich, Germany. https://doi.org/10.1016/j.procir.2016.11.002

Septianto, F., Kemper, J.A. and Northey, G., 2020. Thanks, but no thanks: the influence of gratitude on consumer awareness of food waste. Journal of Cleaner Production 258: 120591. https:// doi.org/10.1016/j.jclepro.2020.120591

Sharma, H.B., Vanapalli, K.R., Cheela, V.R.S., Ranjan, V.P., Jaglan, A.K., Dubey, B., 2020. Challenges, opportunities, and innovations for effective solid waste management during and post COVID-19 pandemic. Resources, Conservation and Recycling 162: 105052. https://doi.org/10.1016/j. resconrec.2020.105052

Smith, T.A. and Landry, C.E., 2021. Household food waste and inefficiencies in food production. American Journal of Agricultural Economics 103(1): 4-21. https://doi.org/10.1111/ajae.12145

Stock, T. and Seliger, G., 2017. Opportunities of sustainable manufacturing in Industry 4.0. Procedia CIRP 40: 536-541. https:// doi.org/10.1016/j.procir.2016.01.129
Stratman, J. and Novak, J., 1973. Trash compactor. U.S. Patent 3,741,108, issued June 26.

Thoben, K.D., Wiesner, S. and Wuest, T., 2017. Industrie 4.0 and smart manufacturing-a review of research issues and application examples. International Journal of Automation and Technology 11(1): 4-16. https://doi.org/10.20965/ijat.2017. p0004

Tosarkani, B.M. and Amin, S.H., 2018. A possibilistic solution to configure a battery closed-loop supply chain: multi-objective approach. Expert Systems with Applications 92: 12-26. https:// doi.org/10.1016/j.eswa.2017.09.039

Valenzuela, J., Alfaro, M., Fuertes, G., Vargas, M. and Navarrete, C.S., 2021. Reverse logistics models for the collection of plastic waste: a literature review. Waste Management \& Research Journal 40(8): 403-418.

Vanapalli, K.R., Sharma, H.B., Ranjan, V.P., Samal, B., Bhattacharya, J., Dubey, B.K. and Goel, S., 2021. Challenges and strategies for effective plastic waste management during and post COVID19 pandemic. Science of the Total Environment 750: 141514. https://doi. org/10.1016/j.scitotenv.2020.141514

Waqas,M.,Nizami,A.S.,Aburiazaiza,A.S.,Barakat,M.A.,Ismail,I.M.I. and Rashid, M.I., 2017. Optimization of food waste compost with the use of biochar. Journal of Environmental Management 216: 70-81. https://doi.org/10.1016/j.jenvman.2017.06.015

Wang, X., Zhao, M. and He, H., 2018. Reverse logistic network optimization research for sharing bikes. Procedia Computer Science 126: 1693-1703. https://doi.org/10.1016/j. procs.2018.08.108

Werffa, E.V.D., Vrielinga, L., Zuijlenb, B.V. and Worrellb, E., 2019. Waste minimization by households-a unique informational strategy in the Netherlands. Resources, Conservation \& Recycling 144: 256-266. https://doi.org/10.1016/j.resconrec.2019.01.032

Wilkinson, K., 2020. The drawdown review. A. P. D. Publication. Available at: https://drawdo wn.org/drawdown-review.

Ye, Z., Yang, J., Zhong, N., Tu, X., Jia, J. and Wang, J., 2020. Tackling environmental challenges in pollution controls using artificial intelligence: a review. Science of the Total Environment 699: 134279. https://doi.org/10.1016/j.scitotenv.2019.134279

Zhou, L., Du, C., Bai, C. and Song, Y., 2019. An Internet of Things based COPD managing system: its development, challenges and first experiences. Clinical eHealth 2: 12-15. https://doi. org/10.1016/j.ceh.2019. 